\title{
Eksplorasi, isolasi dan identifikasi jamur entomopatogen yang menginfeksi serangga hama
}

\author{
Exploration, isolation and identification of entomopathogenic fungi infecting pest \\ insects
}

\author{
Arsi*, Yulia Pujiastuti, Suparman Surya Hadi Kusuma, Bambang Gunawan \\ Program Studi Proteksi Tanaman, Jurusan Hama dan Penyakit Tumbuhan, Fakultas Pertanian, Universitas Sriwijaya
}

\section{INFORMASI ARTIKEL}

*Korespondensi:

Arsi

arsi@fp.unsri.ac.id

Informasi proses:

Received: 11 Juli 2020

Accepted: 16 Juli 2020

Published: 23 Juli 2020

Cara sitasi:

Arsi, Pujiastuti Y, Kusuma SSH, Gunawan B. 2020. Eksplorasi, isolasi dan identifikasi jamur entomopatogen yang menginfeksi serangga hama. Jurnal Proteksi Tanaman

Tropis $1(2): 70-76$

DOI:

\begin{abstract}
Entomopathogenic fungi are classified as a fungus that infects insect pests. Hyphae color that comes out of the insect's body depends on the type of entomopathogenic fungus that attacks it. The purpose of this research is to explore, isolate and identify entomopathogenic fungi that attack insect pests. Samples of dead insects were taken from vegetable crops in the highlands of Pagaralam City and the lowlands of Ogan Komering Ilir Regency. In addition, exploration is also carried out using insect bait methods. This method is carried out on soils taken from the highlands of the fencealam area and Pekanbaru area. Based on the results of entomopathogenic expolation in vegetable plants that infect insects in the field there are 2 types of fungi that attack the insect. Two types of entomapatogenic fungi were found to have characteristics, namely the first hyphal color is rather green which covers the entire body of the insect and the second is white hyphae. The fungus that attacks the insect, then isolated to the GYA media found two entomopathogenic fungi namely, Metarhizium sp. and Beauveria bassiana. Meanwhile, through insect bait using soil Tenebrio molitor larvae, one species of entomopathogenic fungus was found, namely Metarhizium sp. The most infected T. molitor larvae in the soil of origin of Pekanbaru in the $2^{\text {nd }}$ and $4^{\text {th }}$ weeks, namely, 21.90 and 29.33 tails.
\end{abstract}

Key words: Entomopathogenic fungus; Insect Pest; Tenebrio molitor

\section{Pendahuluan}

Jamur entomopatogen merupakan salah satu jamur yang bersifat heterotrof. Karena sifat heterotroph jamur entomopatogen hidup sebagai parasit pada serangga (Permadi et al., 2019). Pengendalian hayati yang banyak digunakan untuk mengendalikan serangga hama di lapangan yaitu, jamur entomopatogen (Reddy et al., 2016). Pemanfaat jamur entomopatogen untuk mengendalikan serangga memiliki kelebihan dalam kapasitas produksi yang tinggi, siklus dari jamur entomopatogen relatif singkat dan mampu membentuk spora yang tahan terhadap kondisi lingkungan yang buruk (Rosmayuningsih et al., 2014).

Beberapa jamur yang sudah dilakukan penelitian yaitu Beauveria bassiana dan Metarhizium anisopliae yang efektif mengendalikan serangga dari ordo Lepidoptera (Herlinda et al., 2005), (Widiarta dan Kusdiaman. 2005). Menurut Hidayah et al., (2019), Jamur entomopatogen yang digunakan sebagai agens hayati untuk membunuh Lepidiota stigma ada tiga jamur yaitu, $M$. anisopliae, $B$. bassiana dan Streptomyces sp. Berdasarkan hasil penelitian terhadap jamur $B$. bassiana dalam mengendalikan Cylas 
formicarius menggunakan lebih efektif. Di dalam keberhasilan dalam mengendalikan hama tersebut tergantung dengan frekunsi aplikasi jamur tersebut (Prayogo, 2017). Jamur Metarhizium sp. menyerang serangga berbagai ordo yaitu, Lepidoptera, Hemiptera, Diptera dan Coleoptera. Metarhizium sp. banyak di identifikasi dari berbagai hama kumbang dari Ordo Coleoptera, tetapi dalam jamur entomopatogen hanya spesies jamur Metarhizium sp. yang dilaporkan yang paling efektif dalam menginfeksi kelompok dari Family Scarabaeidae (Coleoptera) (Indrayani, 2017). Metarhizium sp. banyak digunakan dalam mengendalikan serangga-serangga hama di lapangan. Menurut Yunizar (2018), mengunakan jamur entomopatogen asal dari larva Oryctes rhinosceros untuk mengendalikan lalat Musca domestica.

Jamur entomopatogen yang banyak digunakan dalam pengendalian serangga hama di lapangan yaitu jamur Metarhizium sp. Jamur ini dapat melakukan penetrasi ke dalam tubuh serangga inang melalui 2 cara yaitu tekanan mekanik dan bantuan toksin yang di keluarkan jamur entomopatogen tersebut (Hasyim et al., 2016). Menurut Septiana et al., (2019), melakukan identifikasi terhadap jamur yang dapat dijadikan sebagai agens hayati yaitu Aspergillus sp., Geotrichum sp. dan Penicillium sp. Jamur menyerang serangga dicirikan dengan tubuh serangga menjadi kaku dan keras, membuat serangga seperti mumi serta dari tubuh serangga tersebut akan keluar hifa yang tergantung dari jamur tersebut yang menyerang serangga (Ayudya et al., 2019).

Menurut Hadi et al. (2016), menyatakan bahwa jamur $M$. anisopliae dan B. bassiana dapat menekan tingkat kerusakan tanaman sawi yang disebabkan oleh Phyllotreta striolata dan Phyllotreta sp. Menurut Permadi et al. (2019) bahwa Metarhizium sp. mempunyai konidia yang memiliki rantai pararel. Rantai pararel ini terbentuk jika konidia terbentuk dalam jumlah banyak. Jamur menyerang serangga dicirikan dengan tubuh serangga menjadi kaku dan keras (Aror, 2017). Serangga tubuhnya seperti mumi dan dari tubuh serangga tersebut akan keluar hifa yang tergantung dari jamur tersebut yang menyerang serangga (Ayudya et al., 2019).

Jamur entomopatogen seperti, $M$. anisopliae dan $B$. bassiana sudah banyak digunakan sebagai bahan aktif bioinsektisida cair. Akan tetapi, apabila kandungan dari bioinsektisida baik makan akan meningkat kerapatan dan viabiltas spora (Triasih et al., 2019). Eksplorasi merupakan salah satu cara atau teknik dalam pengendalian hayati dalam melaksanakan pencarian msush alami. Ekspolasi dapat dilakukan dengan cara mengumpulkan serangga yang terinfeksi di lapangan dan umpan serangga. Eksplorasi merupakan kegiatan yang didasarakan atas adanya fenomena alam yang tidak bisa dilepaskan dari organisme penganggu tanaman dan musuh alamnya. Keberadaan musuh alami di lapangan dapat diperanguhi oleh lingkungan yang ekstrem yang sebaliknya lingkungan yang baik dapat meningkat jumlah musuh alami. Musuh alami di lapangan dapat ditingkat melalui konservasi atau pelestarian yang dapat dilakukan dengan cara menciptakan lingkungan yang kondusif. Eksplorasi musuh alami tersebut dapat dikembangkan dan diperbanyak untuk dimanfaatkan dalam pengendalian. Jamur entomopatogen berasal dari serangga sakit, bagian tanaman dan tanah yang ada sekitar tanaman (Herdatiarni et al., 2014).

Menurut Sijid (2018), eksplorasi jamur entomopatogen dapat dilakukan di rizofer tanaman sayuran dan diketahui ada tiga 3 genus jamur yang dapat menghambat pertumbuhan serangga yaitu, Metarhizium, Beauveria dan Aspergillus. Eksplorasi bertujuan untuk menyeleksi jamur yang menyerang serangga hama di lapangan dari berbagai wilayah memiliki tingkat entomopatogenik. Jamur dan bakteri sangat baik dalam proses pengembangan formulasi menjadi produk yang dapat dimanfaatkan dalam pengendalian hayati (Priyatno et al., 2016). Penerapan pengendalian hayati dimasyarakat masih belum di terima oleh petani, hal ini disebabkan masyarakat belum bisa mengaplikasikan pengendalian hayati di lapangan (Khastini dan Wahyuni, 2017). Tujuan penelitian ini untuk mengeksplorasi, isolasi dan identifikasi jamur entomopatogen yang menyerang serangga.

\section{Metode penelitian}

Lokasi penelitian pada lahan tanaman sayuran di dataran tinggi Kota Pagaralam, dataran rendah Kabupaten Ogan Komering Mir dan Pekanbaru serta Laboratorium Entomopatogen Jurusan Hama dan Penyakit Tumbuhan Fakultas Pertanian, Universitas Sriwijaya, Penelitian ini dilaksanakan dari bulan Juli sampai November 2019.

\section{Eksplorasi jamur entomopatogen dari serangga mati di lapangan.}

Eksplorasi jamur entomopatogen di lapangan dilakukan pada dua tempat yaitu, di daerah dataran rendah Kabupaten Ogan Komering Ilir dan di daerah Dataran Tinggi pada kota Pagaralam. Pengamatan dilakukan pada tanaman sayur-sayuran pada lahan petani pada masing-masing wilayah tersebut. Pengamatan terhadap serangga yang terserang dilakukan untuk mengetahui keberadaan jamur entomopatogen yang menyerang serangga fitofag di lapangan. Serangga yang terserang jamur entomapatogen kemudian dimasukkan ke dalam botol plastik yang ada tutupnya kemudian dibawa ke laboratorium untuk isolasi.

\section{Eksplorasi jamur entomopatogen dari tanah di lapangan.}

Eksplorasi jamur entomopatogen berasal dari tanah dilakukan pada lahan yang terdapat jamur entomo- 
patogen menyerang serangga dan tanah asal Pekanbaru. Untuk tanah asal Pekanbaru merupakan tanah asal perbanyakan $O$. rhinosceros. Selanjutnya tanah tersebut digunakan pada uji umpan serangga menggunakan larva instar ketiga Tenebrio molitor. Larva yang digunakan yang baru ganti kulit sebagai perangkap jamur entomopatogen. Sebelum larva dimasukkan ke dalam kotak plastik yang ukuran $15 \times$ $20 \mathrm{~cm}$. Tanah-tanah tersebut dimasukkan ke dalam kotak plastik sebanyak 30 kotak. Tanah tersebut diambil dari lapangan merupakan tanah yang berasal dari di wilayah tanaman sayuran yang terdapat serangga yang terserang entomopatogen. Tanah yang diambil pada ke dalam $15-20 \mathrm{~cm}$, bertujuan untuk mengetahui asal dari entomopatogen tersebut. Tanah yang diambil sebanyak $15 \mathrm{~kg}$ untuk di bawah ke laboratorium. Kemudian dimasukkan larva T. molitor sebanyak 50 ekor per kotak plastik. Setelah itu, disemprot dengan air untuk menjaga kelembaban. Kemudian diamati setiap hari dan dicatat serangga yang terinfeksi dan di ambil mengunakan pinset.

\section{Isolasi dan identifikasi jamur entomopatogen di laboratorium}

Serangga yang mati baik dari eksplorasi di lapangan maupun umpan serangga diambil. Serangga yang terserang sebelum ditanam pada media terlebih dahulu disterilkan. Pertama serangga tersebut direndam pada larutan klorok selama 3 menit, setelah itu dikeringanginkan diatas tisu. Kemudian serangga tersebut direndam lagi ke dalam air steril selama 3 menit, lalu dikeringanginkan. Serangga tersebut kemudian di tanam pada media Glucose Yeast Agar (GYA) di dalam Laminar air flow. Komposisi media GYA terdiri dari tepung jangkrik $1,3 \mathrm{~g}$, Agar $5 \mathrm{~g}$, glukosa $2,5 \mathrm{~g}$, yeast $1 \mathrm{~g}$ dan $250 \mathrm{~mL}$ aquadest. Lalu media tersebut di autoclave dengan tekanan $1 \mathrm{~atm}$. Setelah itu dimasukan ke dalam laminar airflow, lalu media dituang ke dalam cawan Petri yang sbelumnya sudah diberi antibiotik. Setelah medianya keras kemudian serangga-serangga yang terinfeksi ditanam pada media GYA. Lalu di identifikasi jamur yang menyerang serangga tersebut.

\section{Analisis Data}

Data hasil penelitian dianalisi menggunakan uji $\mathrm{T}$ terhadap larva T. molitor hasil pengujian terhadap entomopatogen asal tanah

\section{Hasil dan Pembahasan}

Berdasarkan hasil eksplorasi jamur entomopatogen terhadap serangga mati di lapangan pada tanaman sayuran terdapat 2 jenis jamur yang menginfeksi serangga. Dua jenis jamur entomapatogen yang ditemukan memiliki ciri-ciri yaitu, pertama warna hifa agak hijau yang menutupi seluruh tubuh serangga dan yang kedua hifa yang berwarna putih. Jamur yang menyerang serangga, kemudian di isolasi ke media GYA ditemukan dua jenis jamur yaitu, Metarhizium sp. dan B. bassiana. Kedua jenis jamur entomopatogen menyerang larva Spodoptera litura pada pertanaman terung (Gambar 1).

Larva yang terinfeksi jamur entomopatogen pada tanaman terung letaknya bervariasi. Larva tersebut ditemukan di bawah daun, pada permukaan dan pangkat daun. Larva yang terserang akan menuju ke bagian atas tanaman, kemudian larva tersebut akan mati. Larva yang mati akan menempel pada daun, kemudian setelah beberapa hari hifa akan keluar. Hifahifa yang keluar akan memenuhi tubuh larva serangga. Lalu jamur entomopatogen akan membentuk spora. Spora-spora akan terbang ditiup oleh angin, kemudian spora tersebut akan menempel pada daun atau bagian tanaman. Sehingga serangga hama yang datang ke tanaman dan memakan bagian tanaman tersebut. Lalu serangga tersebut akan terinfeksi oleh jamur yang menempel di bagian tanaman. Spora ini juga bisa langsung nempel pada larva atau serangga yang disebarkan oleh angin. Jamur entomopatogen akan merangsang larva untuk menuju ke atas bagian tanaman, karena untuk menyebarkan spora ke larva yang sehat

Berdasarkan hasil penelitian terhadap entomopatogen yang menyerang serangga di lapangan sangat sedikit ditemukan serangga yang terinfeksi entomopatogen. Pada wilayah Ogan komering Ilir merupakan wilayah dataran rendah. Berdasarakan pengamatan yang dilakukan terhadap 4 tanaman sayuran pada wilayah tersebut tidak ditemukan jamur entomopatogen. Sedangkan wilayah dataran tinggi yaitu, Pagaralam yang ditemukan hanya 1 jenis tanaman yang ada serangga yang terinfeksi jamur entomopatogen yaitu, tanaman terong. Sedangkan 3 jenis tanaman tidak ditemukan serangga yang terinfeksi. Keberadaan entomopatogen pada lahan pertanian masing-masing wilayah tanaman sayuran hampir tidak bisa ditemukan. Hal ini, disebabkan oleh faktor lingkungan yang tidak mendukung untuk perkembangan jamur entomopatogen di lapangan. Faktor lingkungan yang sangat berpengaruh terhadap keberadaan jamur entomaptogen di lapangan cuaca. Pada penelitian ini waktu pengamatan yang dilakukan pada musim kemarau. Dimana pada musim kemarau cuaca sangat panas, sehingga bisa memperngaruhi perkembangan entomopatogen yang menginfeksi serangga dan keberadaannya di lapangan. Selain faktor cuaca, pemakaian pestisida yang terus-menerus pada lahan pertanian dapat menyebabkan jamur entomopatogen sulit berkembang. Khusus pemakaian fungisida, fungisida dapat membunuh jamur entomopatogen. Pemakaian pestisida dapat menimbulkan berdampak negatif bagi lingkungan, resisten dan resusjensi pada serangga. Selain itu, dapat menyebabkan musuh alami yang di lapangan ikut menjadi mati (Tabel 1). 
Tabel 1. Entomopatogen yang menyerang serangga pada dataran tinggi dan dataran rendah pada tanaman sayuran

\begin{tabular}{|c|c|c|c|c|c|c|c|c|c|}
\hline \multirow{2}{*}{ Wilayah } & \multirow{2}{*}{ Tanaman } & \multicolumn{8}{|c|}{ Entomopatogen yang menyerang serangga pengamatan ke... } \\
\hline & & 1 & 2 & 3 & 4 & 5 & 6 & 7 & 8 \\
\hline \multirow[t]{4}{*}{ Ogan Komering Ilir } & Kacang panjang & 0,00 & 0,00 & 0,00 & 0,00 & 0,00 & 0,00 & 0,00 & 0,00 \\
\hline & Jagung & 0,00 & 0,00 & 0,00 & 0,00 & 0,00 & 0,00 & 0,00 & 0,00 \\
\hline & Mentimun & 0,00 & 0,00 & 0,00 & 0,00 & 0,00 & 0,00 & 0,00 & 0,00 \\
\hline & Terong & 0,00 & 0,00 & 0,00 & 0,00 & 0,00 & 0,00 & 0,00 & 0,00 \\
\hline \multirow[t]{4}{*}{ Pagaralam } & Tomat Ranti & 0,00 & 0,00 & 0,00 & 0,00 & 0,00 & 0,00 & 0,00 & 0,00 \\
\hline & Terong & 24,00 & 15,00 & 20,00 & 25,00 & 28,00 & 25,00 & 27,00 & 26,00 \\
\hline & Daun Bawang & 0,00 & 0,00 & 0,00 & 0,00 & 0,00 & 0,00 & 0,00 & 0,00 \\
\hline & Seledri & 0,00 & 0,00 & 0,00 & 0,00 & 0,00 & 0,00 & 0,00 & 0,00 \\
\hline
\end{tabular}

Berdasarkan hasil pengamatan dan wawancara di lapangan pada lahan petani. Bahwa petani tidak pernah melakukan pengendalian mengunakan musuh alami, seperti jamur entomopatogen. Petani tidak mengetahui bahwa larva-larva yang dilapangan berwarna putih dan hijau tersebut mati dikarenakan serangan jamur entomopatogen. Jamur entomopatogen yang menyerang tanaman berasal dari alam. Karena jamur entomopatogen tersebut berasal dari tanah, sehingga mudah untuk menginfeksi larva serangga $S$. litura. Hal ini disebabkan larva-larva tersebut pada siang hari akan masuk ke dalam tanah. Setelah menjelang malam larva-larva tersebut akan naik ke tanaman.

Petani belum pernah melakukan pengendalian hayati menggunakan jamur entomopatogen. Jamur entomopatogen belum banyak diketahui oleh petani dan begitu juga manfaatnya dari jamur tersebut. Menurut Aisyah dan Astuti (2019), berdasarkan hasil pre-test menunjukkan bahwa sebagai masyarakat masih ragu-ragu sebanyak $66,7 \%$ dan belum mengetahui sebanyak 33,3 \%. Sehingga keberadaan agens hayati untuk mengendalikan hama di lapangan agak sulit dilakukan. Pada tanaman terong ditemukan jamur entomopatogen yang menyerang larva serangga. Larva serangga tersebut banyak sekali terserang jamur entomopatogen, sedangkan pada tanaman lain tidak ditemukan. Berdasarkan hasil wawancara dengan pemilik kebun mereka sudah 1 bulan lebih tidak menggunakan pestisida dalam mengendalikan serangga. Di lahan tersebut juga banyak ditemukan larva-larva dari $S$. litura. Sedangkan pada tanaman sayuran yang lain tidak ditemukan larva serangga dan para petani masih melakukan pengendalian menggunakan pestisida.

Berdasarakan hasil pengamatan di lapangan dari 8 lahan tanaman sayuran hanya terdapat 1 lahan tanaman sayuran terserang jamur entomopatogen. Lahan yang terserang jamur entomopatogen merupakan lahan pertanaman terong. Karena lahan terong di pagaralam yang banyak terserang jamur entomopatogen, sehingga tanah di lahan tanaman terong di ambil untuk lihat apakah di dalam tanah tersebut terdapat jamur entomopatogen. Begitu tanah asal Pekanbaru, terdapat serangga yang terserang jamur entomopatogen sehingga kedua tanah tersebut dibandingkan untuk melihat jamur entomopatogen yang ada di dalam tanah dengan cara umpan serangga. Umpan serangga mengunakan larva T. molitor sebagai serangga uji.

Berdasarkan hasil uji t terhadap dua lahan yang digunakan sebagai eksplorasi berbeda nyata antara tanah pagaralam dengan tanah riau. Pengamatan dua minggu setelah aplikasi paling tinggi pada tanah pekanbaru dengan rata-rata larva yang terinfeksi yaitu, 21,90 ekor. Begitu juga pada 4 minggu tanah asal dari pekanbaru tertinggi terserang jamur entomopatogen yaitu 29,33 ekor. Berdasarkan hasil penelitian bahwa jamur entomopatogen $M$. anisopliae yang menyerang larva L. stigma memerlukan waktu selama 2 minggu untuk dapat membunuh larva serangga tersebut. Sedangkan jamur B. bassiana membutuhkan waktu 3 minggu untuk menginfeksi larva L. stigma (Hidayah et al., 2019). Berdasarkan hasil uji t terhadap tanah pagaralam dan tanah pekanbaru menunjukkan nilai rata-rata yang berbeda. Perbedaan serangga yang terinfeksi jamur entomopatogen memerlukan waktu untuk mematikan serangga. Konidia memerlukan waktu untuk membunuh setelah menepel ditubuh serangga (Permadi et al., 2019). Hal ini dapat menunjukkan tanah asal pekanbaru lebih dominan dalam menginfeksi larva (Tabel 2).

Hal ini diduga bahwa tanah asal Pekanbaru banyak mengandung bahan organik dan jarang menggunakan pestisida sintetik. Sedangkan tanah asal Pagaralam diduga banyak menggunakan pestisida dalam menggendalikan serangga hama. Sehingga mortalitas juga sangat berpengaruh terhadap serangga tersebut dan keberadaan jamur entomopatogen di lapangan. Lahan yang tidak menggunakan pestisida dan pupuk anorganik dapat menciptakan tanaman yang sehat dan tanah juga banyak mengandung mikroorganisme yang dapat membantu kesuburan tanah. Sistem pertanian organik salah satu pertanian yang ramah lingkungan (Margolang et al., 2015). Selain itu juga, keberadaan spora di dalam tanah yang banyak bisa meningkatkan serangga yang terinfeksi jamur entomopatogen sangat cepat (Pramono dan Purnomo 2019). Menurut Permadi 
Tabel 2. Hasil Uji t terhadap asal tanah yang berbeda terhadap larva T. molitor

\begin{tabular}{cccccr}
\hline \multirow{2}{*}{ Pengamatan Minggu ke... } & \multicolumn{2}{c}{ Rerata Larva yang terinfeksi Jamur Entomopatogen (Ekor) } & \multirow{2}{*}{ T Hitung } & \\
\cline { 2 - 4 } & Tanah Pagaralam & Tanah Pekanbaru & & 28,48 & 0,00000000007 \\
\hline 2 & 8,00 & 21,90 & 3,24 & 0,009 \\
\hline
\end{tabular}
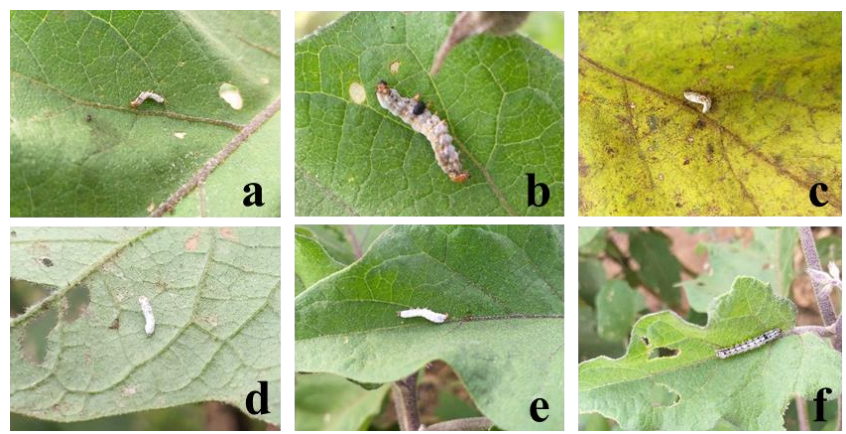

Gambar 1. Larva Spodoptera litura Fabr. yang terserang jamur entomopatogen di lapangan (a), Larva yang terserang jamur entomopatogen Metarhizium sp. yang hifa baru muncul (b), Larva yang terserang jamur entomopatogen Metarhizium sp. mulai menutupi tubuh larva (c), Larva yang terserang entomopatogen Metarhizium sp. dimana hifa sudah tumbuh sempurna (d), larva yang terserang entomopatogen Beauveria bassiana (e), larva yang sehat (f).

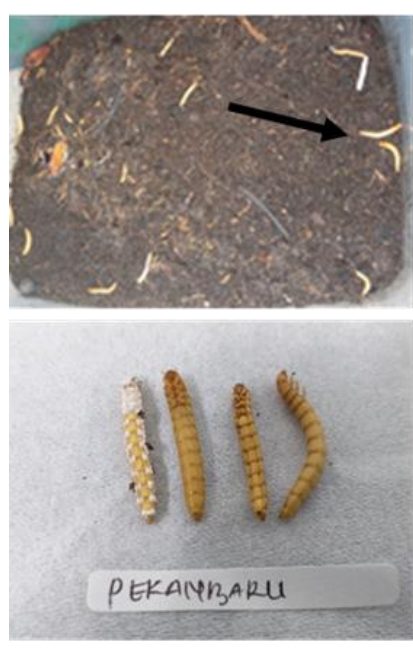

a

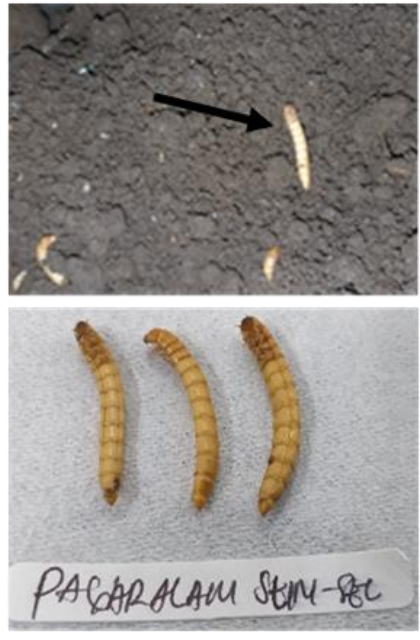

\section{b}

Gambar 2. Larva yang mati akibat terserang jamur entomopatogen dari eksplorasi tanah Riau (a) dan tanah asal Pagaralam (b)

et al. (2018), menyatakan bahwa lahan yang tidak diaplikasikan pestisida dapat meningkatkan mikroorganisme di dalam tanah tersebut. Hal ini dikarenakan mikroorganisme tersebut tidak musnah akibat residu pestisida.

Kerapatan spora yang tinggi pada masing-masing perlakuan bisa menyebabkan tingkat mortalitas berbeda. Hal ini disebabkan oleh tingkat virulensi dari jamur entomopatogen. Bisa dikarenakan perlakuan yang berbeda dimana proses perendaman pakan yang diberikan pada serangga lebih cepat diserap oleh pakan. Sehingga serangga langsung memakan pakan yang sudah ada jamur entomopatogen, dengan dimakan pakan tersebut memudahkan jamur berkecambah di dalam tubuh serangga dan membuat serangga cepat mati. Sedangkan jamur entomopatogen yang menempel di tubuh serangga memerlukan waktu dan dapat di pengaruhi oleh suhu dan kelembaban (Ardiyati et al., 2015). Berdasarkan eksplorasi terhadap tanah yang diambil dari dua lahan yang berbeda di dapat serangga yang mati akibat jamur entomopatogen. Ciri-ciri serangga yang terserang jamur entomopatogen, pertama bergerak lambat, kemudian serangga tersebut mati, serangga yang mati tubuhnya keras dan kaku. Tubuh serangga tersebut tidak berubah, yaitu warna tetap orange. Setelah 2-3 hari baru mulai warna berubah menjadi putih yang ditutupi oleh hifa jamur (Gambar 2).

Hari kelima miselia cendawan berwarna putih mengalami perubahan menjadi warna hijau. Menurut Permadi et al. (2019), serangga yang terserang jamur M. anisopliae setelah lima hari tubuh diselimuti oleh hifa jamur yang berwana hijau. Serangga yang terserang jamur entomopatogen, akan mengalami perubahan, yaitu serangga yang ada di dalam tanah akan naik pada permukaan tanah, terus serangga tersebut akan mengalami mumifikasi (Wibowo et al., 2018). Serangga yang termumifikasi akan mengalami perubahan warna pada tubuhnya (Ulya et al., 2016).

Eksplorasi tanah asal pekanbaru menunjukkan gejala serangga yang mati pertama tubuh serangga tersebut keras dan kaku. Tubuh serangga tetap tidak ada perubahan yaitu warna tetap orange. Kemudian setelah 2-3 hari tubh serangga akan mengeluarkan hifa putih (Gambar 2). Larva serangga yang mati pada eksplorasi tanah pagaralam menunjukkan gejala yang sama dengan seranggga yang menyerang pada tanah pekanbaru. Serangga yang terinfeksi jamur entomopatogen mati setelah 1-2 minggu. Akibatnya serangga yang mati menjadi kaku. Serangga yang mati kemudian diambil dan di tanam pada media. Kemudian dilakukan isolasi sampai tubuh biakan murni. Serangga-serangga yang mati kemudian disimpan sebagian dan sebagian lagi dilakukan isolasi (Gambar 3).

Berdasarkan hasil identifikasi terhadap serangga yang terserang jamur entomopatogen terdapat 2 spesies jamur. Jamur entomopatogen yang menyerang pada larva serangga yaitu, Metarhizium sp. dan B. bassiana. Ciri-ciri kedua jamur yang menyerang larva serangga 


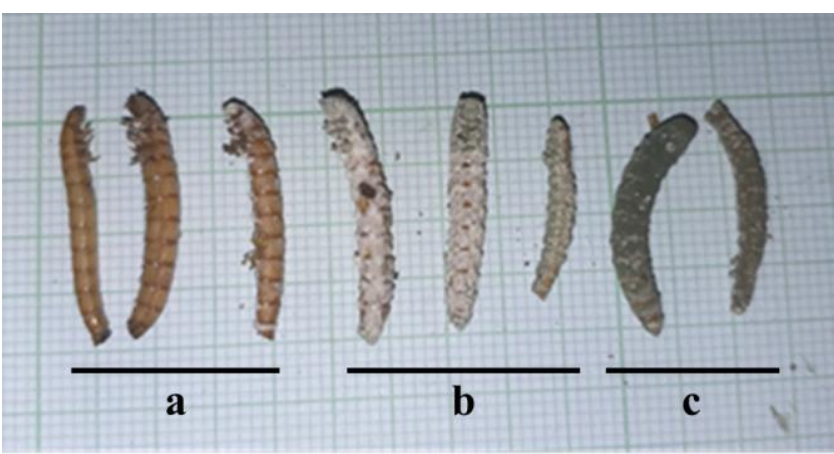

Gambar 3. Larva T. monitor yang terinfeksi jamur entomopatogen (a) larva di hari pertama, (b) larva di hari 2-3 dan (c) larva di hari 5.

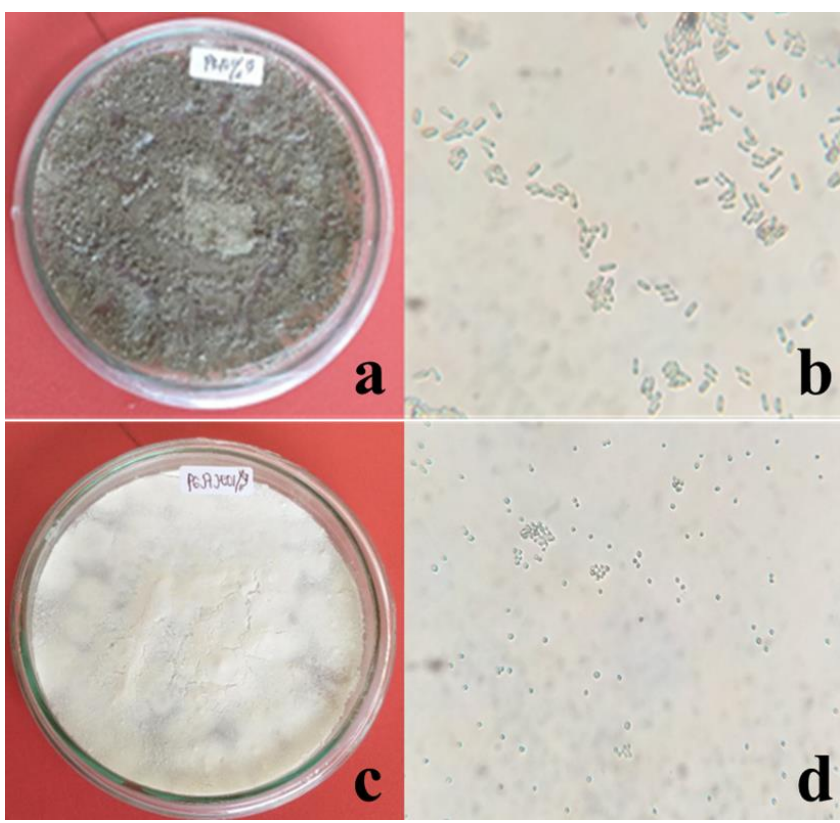

Gambar 4. Jamur Entomopatogen Metarhizium sp. (a), Konidia jamur Entomopatogen Metarhizium sp. (b), Jamur Entomopatogen Beauveria bassiana (c) dan Konidia Jamur Entomopatogen Beauveria bassiana (d) (Pembesaran 40×)

pada awal hampir sama, akan tetapi untuk jamur Metarhizium sp. lama-kelamaan larva yang terinfeksi akan berubah warna dari putih hifanya menjadi warna hijau. Sedangkan pada jamur B. bassiana hifa nya tetap berwarna putih bersih. Selain itu perbedaan konidianya juga jelas sekali dimana Metarhizium sp. berbentuk panjang seperti basil, sedangkan pada jamur $B$. bassiana berbentuk oval (Safitri et al., 2018; Khastini dan Wahyuni 2017) (Gambar 4).

Dengan demikian dapat disimpulkan bahwa jamur entomopatogen yang di dapat langsung dari lapangan terdapat 2 jenis jamur yaitu Metarhizium sp. dan $B$. bassiana. Kedua jenis jamur tersebut diperoleh dari tanaman terung di Pagaralam. Serangga yang serang oleh jamur entomopatogen tersebut adalah larva $S$. litura, sedangkan di laboratorium terdapat 1 jenis jamur entomopatogen dari lahan Pekanbaru dan lahan
Pagaralam yaitu, Metarhizium sp. Larva T. molitor yang terinfeksi pada minggu kedua dan minggu keempat di tanah lahan Pekanbaru berturut-turut sebanyak 21,90 dan 29,33 ekor.

\section{Pernyataan tidak ada konfik kepentingan}

Semua penulis artikel ini menyatakaan bahwa tidak ada konflik kepentingan terkait penelitian dan hasil penelitian ini.

\section{Ucapan Terima kasih}

Direktorat Jenderal Penguatan Riset dan Pengembangan, Kementerian Riset, Teknologi, dan Pendidikan Tinggi dan Program Studi Proteksi Tanaman, Jurusan Hama dan Penyakit Tanaman, Fakultas Pertanian, Universitas Sriwijaya

\section{DAFTAR PUSTAKA}

Aisyah SN, Astuti A. 2019. Peningkatan kemandirian kelompok petani pengembang agensia hayati dadi makmur untuk memproduksi aktivator jamur entomopatogen Beauveria bassiana skala rumah tangga. Jurnal Bakti Saintek: Jurnal Pengabdian Masyarakat Bidang Sains dan Teknologi. 3(2): 67-72.

Ardiyati AT, Mudjiono G, Himawan T. 2015. Uji patogenisitas jamur entomopatogen Beauveria bassiana (Balsamo) Vuillemin pada jangkrik (Gryllus sp.) (Orthoptera: Gryllidae). Jurnal Hama dan Penyaki Tumbuhan. 3(3): 43-51.

Aror APF. 2017. Pemanfaatan jamur entomopatogen Beauveria bassiana (Balsamo) Vuillemin terhadap larva Plutella xylostella (L) di laboratorium terhadap Larva Plutella xylostella (L.). Jurnal Cocos. 1(2): 1-12.

Ayudya DWIR, Herlinda S, Suwandi S. 2019. Insecticidal activity of culture filtrates from liquid medium of Beauveria bassiana isolates from South Sumatra (Indonesia) wetland soil against larvae of Spodoptera litura. Jurnal Biodiversitas. 20(8): 21012109.

Hadi M.S, Himawan T, Hiola IR. 2016. Efektivitas jamur Beauveria bassiana (BALS.) VUILL. dan Metarhizium anisopliae untuk mengendalikan hama Phyllotreta spp. (Coleoptera: Chrysomelidae) pada tanaman sawi (Brassica sinensis L.) di Trawas, Mojokerto. Jurnal Hama dan Penyakit Tumbuhan. 4(2): 102-108.

Hasyim A, Setiawati W, Hudayya A, Luthfy N. 2016. Sinergisme jamur entomopatogen Metarhizium anisopliae dengan insektisida kimia untuk meningkatkan mortalitas ulat bawang Spodoptera exigua. Jurnal Hortikultura. 26(2): 257266 .

Herdatiarni F, Himawan T, Rachmawati, R. 2014. Eksplorasi cendawan entomopatogen Beauveria sp. menggunakan serangga umpan pada komoditas jagung, tomat dan wortel organik di Batu, Malang. Jurnal Hama dan Penyakit Tumbuhan. 1(3): 1-11.

Herlinda S, Era MS, Yulia P, Suwandi, Elisa N, Anung R. 2005. Variasi virulensi strain strain Beauveria bassiana (Bals.) Vuill. terhadap larva Plutella xylostella (L.) (Lepidoptera: Plutellidae). Agritrop. 24(2): 52-57.

Hidayah A., Harijani W, Widajati W, Ernawati D. 2019. Potensi jamur entomopatogen Metarhizium anisopliae, Beauveria 
bassiana dan Streptomyces sp. terhadap mortalitas Lepidiota stigma pada tanaman tebu. Plumula 7(2): 64-72.

Indrayani I. 2017. Potensi jamur Metarhizium anisopliae (Metsch.) Sorokin untuk pengendalian secara hayati hama uret tebu Lepidiota stigma (Coleoptera: Scarabaeidae). Perspektif 16(1): 24-32.

Khastini RO, Wahyuni I. 2017. Eksplorasi keragaman fungi entomopatogen di Desa Cikeusik-Baduy Dalam, Banten. Jurnal Scientium 6(1): 1-10.

Khodijah, Herlinda S, Irsan C, Pujiatuti Y, Thalib R. 2012 Arthropoda predator penghuni ekosistem perwasahan lebak dan pasang surut Sumatera Selatan. Jurnal Lahan Suboptimal. 1(1): 57-63.

Margolang R., Jamilah J, Sembiring M. 2015. Karakteristik beberapa sifat fisik, kimia, dan biologi tanah pada sistem pertanian organik. Jurnal Agroekoteknologi Universitas Sumatera Utara 3(2): 717-723.

Permadi MA, Lubis RA, Sari D. 2018. Eksplorasi cendawan entomopatogen dari berbagai rizosfer tanaman Hortikultura di beberapa wilayah Kabupaten Mandailing Natal Provinsi Sumatera Utara. Jurnal AGRITECH XX(1): 23-32

Permadi MA, Lubis RA, Siregar IK. 2019. Studi keragaman cendawan entomopatogen dari berbagai rizosfer tanaman hortikultura di Kota Padangsidimpuan. Jurnal Penelitian dan Pembelajaran MIPA 4(1): 1-9.

Prayogo Y. 2017. Perbandingan metode aplikasi jamur entomopatogen Beauveria bassiana untuk pengendalian Cylas formicarius (Coleoptera: Curculionidae). Jurnal Hama dan Penyakit Tumbuhan Tropika 17(1): 84-95.

Pramono SB, Purnomo H. 2020. Patogenisitas jamur entomopatogen Aschersonia sp. sebagai pengendalian hama kutu sisik Citricola Coccus pseudomagnoliarium (Kuw.) (Homoptera: Coccidae) pada tanaman jeruk. Jurnal Pengendalian Hayati 2(1): 17-22.

Priyatno TP, Samudrai IM, Manzila I, Susilowati DN, Suryadi Y 2016. Eksplorasi dan Karakterisasi entomopatogen asal berbagai inang dan lokasi. Jurnal Ilmu-ilmu Hayati 15(1): 6979

Reddy GVP, Antwi FB, Shrestha G, Kuriwada T. 2016. Evaluation of toxicity of biorational insecticides against larvae of the Alfalfa weevil. Toxicology Reports 3: 473-480.

Rosmayuningsih A, Rahardjo BT, Rachmawati R. 2014. Patogenisitas jamur Metarhizium anisopliae terhadap hama kepinding tanah (Stibaropus molginus) (Hemiptera: Cydnidae) dari beberapa formulasi. Jurnal Hama dan Penyakit Tumbuhan 2(2): 28-37.
Safitri A, Herlinda S, Setiawan, A. 2018. Entomopathogenic fungi of soils of freshwater swamps, tidal lowlands, peatlands, and highlands of south Sumatra, Indonesia. Biodiversitas 19(6): 2365-2373.

Septiana N, Rosa E, Ekowati CN. 2019. Isolasi dan identifikasi jamur entomopatogen sebagai kandidat bioinsektisida lalat rumah (Musca domestica). BIOSFER: Jurnal Tadris Biologi 10(1): $87-94$

Sijid STA. 2018. Cendawan Entomopatogen Sebagai Bioinsektisida Terhadap Serangga Perusak Tanaman. Prosiding Seminar Nasional Megabiodeversitas Indonesia. Universitas Islam Negeri Alaudin Makassar, Gowa, 9 April 2018 [Indonesian] Triasih U, Agustina D, Agustina D, Dwiastuti ME., Dwiastuti ME, Wuryantini S, Wuryantini S. 2019. Test of various carrier materials against viability and conidia density in some liquid biopesticides of entomopathogenic fungi. Jurnal Agronida 5(1): 12-20.

Ulya LN, Himawan T, Mudjiono G. 2016. Uji patogenisitas jamur entomopatogen Metarhizium anisopliae (Moniliales: Moniliaceae) terhadap hama uret Lepidiota stigma F. (Coleoptera: Scarabaeidae). Jurnal Hama dan Penyakit Tumbuhan 4(1): 24-31.

Utami RS, Ambarwati R. 2014. Eksplorasi dan karakterisasi cendawan entomopatogen Beauveria bassiana dari Kabupaten Malang dan Magetan. Jurnal Lentera Bio 3(1): 59-66.

Yunizar N, Rahmawati, Kustiati. 2018. Patogenitas isolat jamur entomopatogenik Metarhizium anisopliae terhadap lalat rumah Musca domestica L. (Diptera: Muscidae). Jurnal Protobiont 7(3): 77-82.

Wibowo L, Sudarsono H, Hariri AM, Yasin N, Susilo FX. 2018. Uji virulensi beberapa isolat Metarhizium sp. terhadap Larva Oryctes rhinoceros L. Prosiding Seminar Nasional PEI Cabang Palembang. Palembang, 12-13 Juli 2018 [Indonesian]

Widiarta IN, Kusdiaman D. 2005. Uji lapang kemampuan jamur entomopatogen Metarhizium menekan pemenceran wereng hijau dan menularkan tungro. Laporan Akhir Tahun. Balai Penelitian Tanaman Padi, Sukamandi. 